\title{
Impact of the new criteria for systemic arterial hypertension diagnosis and treatment suggested by the American College of Cardiology/American Heart Association
}

\author{
Martín Rosas-Peralta and Gabriela Borrayo-Sánchez \\ Instituto Mexicano del Seguro Social, "A todo Corazón-Código Infarto" Program, Ciudad de México, Mexico
}

The new report of the American College of Cardiology and the American Heart Association (ACC/AHA) Working Group about clinical practice guidelines for high blood pressure in adults was published online prior to November 13, 2017. The new American recommendation focused on the criterion to define hypertension: $\geq 130 / 80 \mathrm{~mm} \mathrm{Hg}$ is considered the new cutoff point (Table 1), which is not new if we consider that evidence accumulated in the past two decades derived in considering $140 / 90 \mathrm{~mm} \mathrm{Hg}$ as the reference to start medical actions.

With the conventional criteria $(>140 / 0 \mathrm{~mm} \mathrm{Hg}$ ) there were already great challenges for diagnosis, treatment and follow-up of the patient with hypertension. The figure estimated in Mexico in 2017 was 22.2 million hypertensive adults, out of whom nearly half were undiagnosed and only $60 \%$ of those who were diagnosed were on pharmacological treatment and barely more than half had good control figures.

The problem of high blood pressure should be recognized in our country as a social and public health problem, since prevalence is very high and it is the main cardiovascular risk factor, which contributes with $1.5 \%$ of directly-related deaths and plays collaborates to the development of atherosclerosis, which is a primary cause of mortality in Mexico and the world.

In Mexico, the prevalence of arterial hypertension in adults older than 20 years had been approximately $30 \pm 2 \%$, according to 2000, 2006 and 2012 national health surveys. ${ }^{2}$ However, the 2016 National Halfway Health Survey ${ }^{3}$ indicated a prevalence of $25.5 \%$, which is a drastic decrease deriving from methodological aspects. The meaning of this becomes relevant if the fact that arterial hypertension constitutes the most common cardiovascular risk factor associated with coronary artery disease and cardiovascular death is taken into account. ${ }^{4}$

The problem in terms of cardiovascular risk reduction is complex and difficult to address. Unfortunately, systemic arterial hypertension is not an isolated nosological entity; frequently it cohabitates with diabetes, dyslipidemia and obesity. Both in pairs or as metabolic syndrome, these risk factors have common pathophysiological pathways, and they are known to potentiate each other with regard to tissue damage progression. Therefore, a national health strategy requires a comprehensive and global view on systemic arterial hypertension. We consider that numerous efforts have been made worldwide and that each country has understood that its strategies must be unique and special according to its sociodemographic and multifactorial situation.

In our country, the Mexican Institute of Social Security has developed different strategies to improve prevention as a key action to face chronic non-communicable diseases, including hypertension. The updated ACC/AHA guidelines is an extraordinary opportunity to strengthen the preventive programs for high blood pressure control. In this editorial, we analyze the epidemiological situation in Mexico and possible consequences of the new criteria for hypertension diagnosis. Current main strategies that are applied in the Mexican Institute of Social Security to address cardiovascular risk factors are aimed at prevention. This institution strives to address situations such as the change in hypertension diagnostic criteria and new preventive models are underway.
Gac Med Mex. 2018;154:534-538

Contents available at PubMed www.gacetamedicademexico.com 
Table 1. New arterial hypertension classification

\begin{tabular}{lc}
\hline Normal & $<120 / 80 \mathrm{~mm} \mathrm{Hg}$ \\
Elevated & $120-129 /<80 \mathrm{~mm} \mathrm{Hg}$ \\
Stage 1 & $130-139 / 80-89 \mathrm{~mm} \mathrm{Hg}$ \\
Stage 2 & At least $140 / 90 \mathrm{~mm} \mathrm{Hg}$ \\
Hypertensive crisis & $>180 / 120 \mathrm{mg} \mathrm{Hg}$ \\
\hline AHA/ACC, November 2017. &
\end{tabular}

\section{Panorama in different countries}

\section{China $^{5}$}

China has received the new guidelines with concern, since although the prevalence percentage increase is apparently not much, in absolute numbers of millions of patients it turns out to be highly expensive. Nevertheless, in that country, the change of criteria is regarded as beneficial for cardiovascular prevention. The concept of early treatment matches the life course approach proposed in the Chinese call to action of the Commission on Hypertension published in 2016 in the Lancet. $^{3}$

To judge the usefulness and convenience of the new threshold, its influence on short and long-term perspectives has to be considered. The latter, of course, requires time and can only be historically judged according to the incidence of arterial hypertension cardiovascular complications. However, conclusions can be drawn in the short term if the change improves blood pressure control without substantially increasing the cost, the workload and treatment side effects.

When applying the $130 / 80 \mathrm{~mm} \mathrm{Hg}$ threshold to China's national survey most recent data, the prevalence of high blood pressure would rise by approximately 25 to $50 \%$, although the increase in the number of patients that will require treatment is claimed to be marginal (Fig. 1). In fact, in our studies in the general population and in a population of older adults, the increase was 2 and $5.5 \%$, respectively. If less than $50 \%$ of the general population rate with known hypertension in China was taken into account, the increase in the number of treated hypertensive patients would be insignificant. However, this assumption should be measured with caution in practice.

\section{$\operatorname{Japan}^{6}$}

From the point of view of cardiovascular health, stage 1 hypertension earlier detection with the new

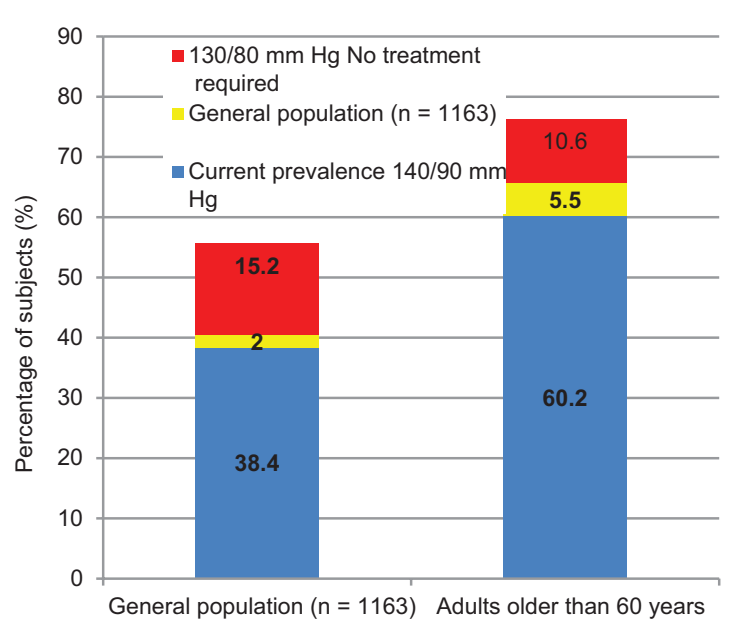

Figure 1. Distribution of hypertensive population with the traditional criterion (140/90 mm Hg) and impact with the new 130/80 mm Hg criterion. In older adults, the high prevalence of hypertension minimizes the impact, but, in Mexico, the hypertensive population is younger than 54 years.

diagnostic threshold (130-139/80-89 mm Hg) -with a precautionary approach to high blood pressure undiagnosed cases (systolic 120-129 mm Hg and diastolic $<80 \mathrm{~mm} \mathrm{Hg}$ )- would be important in order to minimize vascular damage since early ages in life (Fig. 2). At later stages of life, higher levels of pressure are associated with blood pressure higher variability, which could precipitate more cardiovascular events, especially in hypertensive patients with high risk (with diabetes, dyslipidemia and obesity). The Japanese make an interesting analysis of systolic pressure (the most common in that country) and its implications, where the importance of blood pressure home measurement is determined.

\section{India ${ }^{7}$}

India, with a population of 1.32 billion, is experiencing an increase in cardiovascular disease, mainly due to uncontrolled hypertension. Hypertension current prevalence (based on the $\geq 140 / 90 \mathrm{~mm} \mathrm{Hg}$ threshold) in that country is estimated at $28.9 \% .{ }^{3}$ Blood pressure is controlled only in approximately $25 \%$ of treated patients, a figure that will collapse if the new arterial hypertension definition is included.

Unlike the Western world, in India, a mixture of social, cultural and economic factors will make it extremely difficult to manage hypertension in the community with the new lower thresholds. This country is not yet ready to use large scale measurements outside the office. Differential characteristics of the medical 


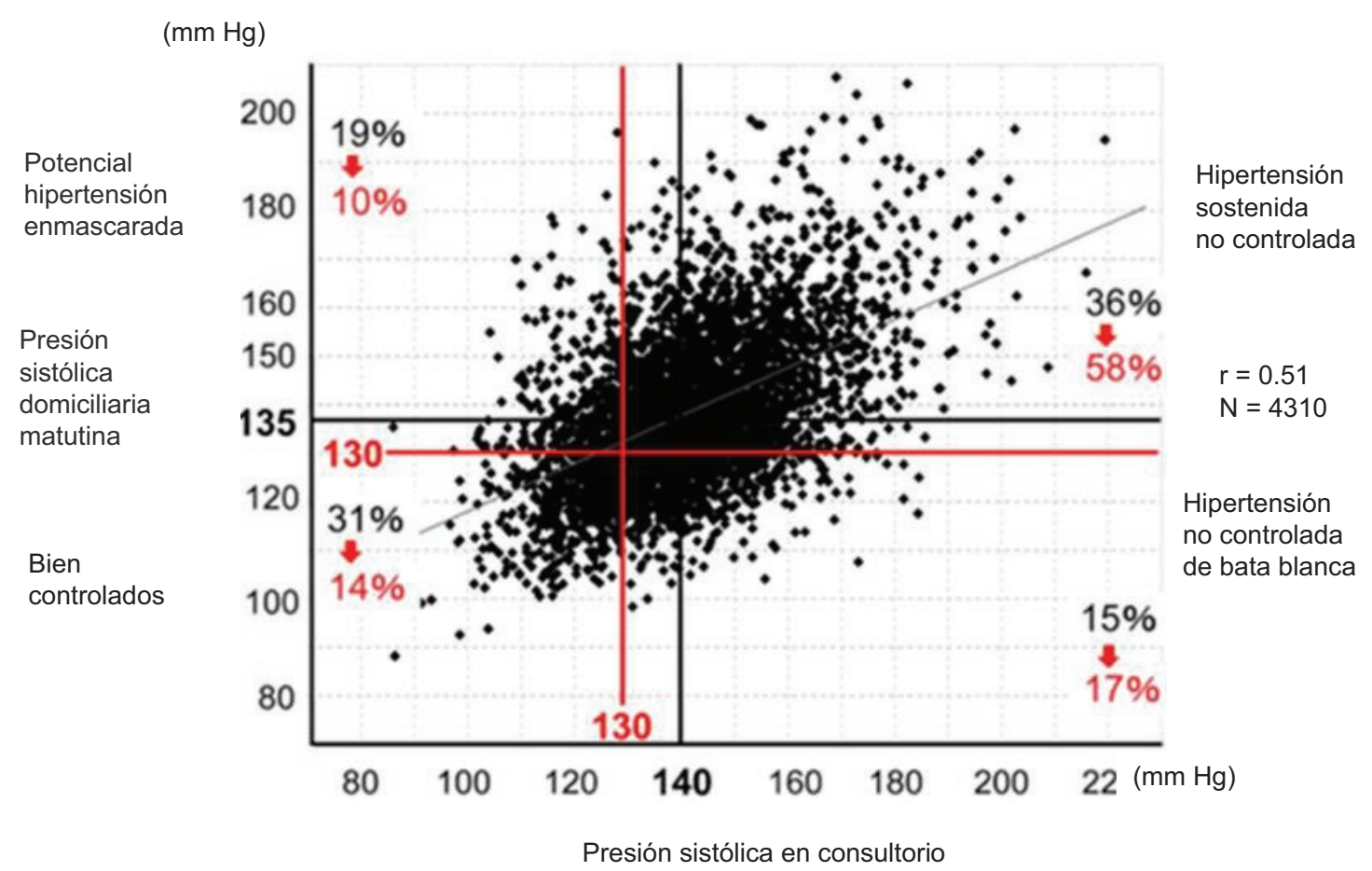

Figure 2. Impact the new criterion will have on systolic pressure and how genuine, white coat and masked hypertension are modified, an important factor to be taken into account.

service will be a great obstacle for rapid adoption of the new parameters in arterial hypertension.

\section{Canada $^{8}$}

The new high blood pressure category and lifestyle modification recommendations are aimed at preventing the development of arterial hypertension. The definition of hypertension as blood pressure $\geq 130 / 80 \mathrm{~mm} \mathrm{Hg}$ resembles that which was suggested in 2016 in Canada after the SPRINT trial, additionally using aortic mean pressure. The new definition makes sense according to several meta-analyses that showed that lowering the blood pressure threshold to $<140 / 90 \mathrm{~mm}$ hg yielded better results. In addition, patients who were recruited in SPRINT with systolic pressure $\leq 132 \mathrm{~mm} \mathrm{hg}$ benefited more than when systolic blood pressure decreased to $<120 \mathrm{~mm} \mathrm{Hg}$. Based on the population estimates deriving from the national health survey and nutrition examination that encompassed from 2011 to 2014 , the prevalence of hypertension will increase from 32 to $46 \%$ due to new hypertensive individuals identified as such with the new criteria. However, many of them belong to hypertension stage 1 and are not necessarily candidates for pharmacotherapy.

Cardiovascular risk is known to start from $120 / 80 \mathrm{~mm}$ hg on. However, high blood pressure is a continuum and the cutoff points to classify and diagnose hypertension have to be taken into account. In other words, in patients with diabetes and blood pressure of $135 / 83 \mathrm{~mm} \mathrm{Hg}$ with evidence of target organ lesion (i.e., microalbuminuria), pharmacological treatment should be considered, in addition to lifestyle changes. On the other hand, in patients with the same blood pressure level but without evidence of target organ lesion and only overweight, changes in weight and lifestyle might be sufficient.

\section{Impact of the new criteria in Mexico}

In Mexico, for example, in mid-2017, there were around 128 million people, $65 \%$ (76 million) corresponded to population older than 20 years. Prehypertension, also known as borderline blood pressure, was considered in the previous Eighth Joint National Committee report and its prevalence was reported to be approximately 25 to $30 \%$ in adult population.

In Mexico, the prevalence of prehypertension was $37.5 \%(95 \%$ confidence interval $[\mathrm{Cl}]=36.0-39.0)$, $46.7 \%$ corresponded to men $(95 \% \mathrm{Cl}=44.1-49.4)$ and $33.2 \%$ to women $(95 \% \mathrm{Cl}=31.5-5.0){ }^{.}$This situation is dramatic, since $37 \%$ of prehypertension in Mexico represents around 30.9 million adult population. With prevalence estimated at $30 \%$ according to 
the $140 / 90 \mathrm{~mm} \mathrm{Hg}$ criterion, around 22.8 million correspond to the hypertension diagnosis, but with the new AHA criteria, the population with hypertension will be at least the double. In other words, we are going to require prevention and treatment programs for around 53 million adults in Mexico. This is a real epidemiological alert that will require new strategies to face an old problem with new diagnostic-therapeutic challenges.

Although the ACC/AHA ${ }^{1}$ approach seeks to address preventive and non-pharmacological actions with stronger emphasis in order to treat the implications of real hypertension in countries like Mexico, it represents an important challenge for public health. The need to establish a position is clear and necessary.

\section{Stage 1 of the new criteria in Mexico: who are candidates for pharmacotherapy?}

One relevant aspect is that, unlike other countries, arterial hypertension occurs more frequently in subjects younger than 54 years. Our statistics of patients who are carriers of diabetes, dyslipidemia and obesity, make for the hypertensive population to be located within the population with higher probability of cardiovascular risk. Therefore, each case must be individualized and stage I patients should not be regarded as only requiring non-pharmacological treatment; on the contrary, the search for target organ damage, such as retinopathy or microalbuminuria, or data consistent with ventricular hypertrophy, which force pharmacological treatment, should be intensified.

\section{Current actions in Mexico}

The epidemiological transition of diseases in Mexico has been recognized since late last century. National health surveys allowed the government of our country to establish health policies specifically aimed at dealing with this new pandemic. At the beginning of this $21^{\text {st }}$ century, integrated health programs such as PREVENIMSS emerged, which is recognized as a strategy for the provision of services whose general purpose is the systematic and orderly provision of related actions, such as health promotion, nutritional surveillance, prevention, detection and control of diseases and reproductive health, which stimulate self-care culture. Currently, the results of this strategy are highly relevant

However, despite the improvement in timely detection of chronic diseases, the great challenge is to achieve even higher numbers of treated and controlled patients, in order to avoid the generation of late complications such as myocardial infarction and cerebral infarction, as well as peripheral artery disease, kidney failure and blindness secondary to hypertensive and diabetic retinopathy. The online training systems have allowed achieving larger coverage and seeking to standardize knowledge and direct actions in the operational field.

Constant alert regarding the control of hypertension, diabetes, obesity, dyslipidemia and tobacco consumption generated the search for alternatives to deal with two fronts at the same time: timely detection and appropriate risk stratification and increasing the percentage of long-term cardiovascular risk factors control. ${ }^{10}$ Recently, a special issue was published in a journal focusing on the National Consensus on Arterial Hypertension in Mexico and the specific clinical situation. ${ }^{11}$

\section{Preventive model}

The Mexican Institute of Social Security adjusted its model of care from curative to preventive in order to deal with the growth of the main four chronic degenerative diseases (diabetes, cardiovascular conditions and breast and prostate cancer), which are the main causes of death in the country. ${ }^{12-14}$ The new model seeks to deploy medical brigades at workplaces and create new specialized medicine clinics, with the support of an intelligence unit that will focus on follow-up by means of an electronic platform and real-time personalized data, in order to detect potential risks of affiliates in relation to these diseases. The development of metabolic control ambulatory centers with artificial intelligence units represents a breakthrough in this institution.

\section{The future}

Prevention is a cornerstone in the care of the patient at risk for developing a disease and in avoiding complications in those who are already carriers thereof. It is no novelty that systemic arterial hypertension is one of the main cardiovascular risk factors. It is necessary keeping in mind that the disease is a continuum and that although the risks start at a blood pressure of $120 / 80 \mathrm{~mm} \mathrm{Hg}$, each case must be individualized and correctly stratified, in order for preventive measures to be established as a first step. In all patients with hypertension, changes in eating habits and physical activity should be established, unless contraindicated. 
On follow-up, the generation of cohorts will be necessary in order to know the impact of pharmacological measures.

\section{References}

1. Whelton PK, Carey RM, Aronow WS, Casey DE Jr, Collins KJ, et al 2017 ACC/AHA/AAPA/ABC/ACPM/AGS/APhA/ASH/ASPC/NMA/PCNA Guideline for the prevention, detection, evaluation, and management of high blood pressure in adults: a report of the American College of Cardiology/American Heart Association Task Force on Clinical Practice Guidelines. Hypertension. 2018;71(6): e13-e115.

2. Instituto Nacional de Salud Pública. Ensanut 2012. Hipertensión arterial en adultos mexicanos: importancia de mejorar el diagnóstico oportuno y el control. Disponible en: https://ensanut.insp.mx/doctos/analiticos/HypertensionArterialAdultos.pdf.

3. Instituto Nacional de Salud Pública. Encuesta Nacional de Salud y Nutrición de Medio Camino 2016. México: INSP; 2016. Disponible en https://www.gob.mx/salud/documentos/encuesta-nacional-de-salud-y-nutricion-de-medio-camino-2016.

4. Velázquez-Monroy $O$, Rosas-Peralta $M$, Lara-Esqueda $A$ Pastelín-Hernández G, Attie $F$, et al. Hipertensión arterial en México: resultados de la ENSA 2000. Arch Cardiol Mex. 2002;72:71-84.

5. Wang Ji-Guang, Lisheng LA. Global impact of 2017 American College of Cardiology/American Heart Association Hypertension Guidelines: a perspective from China. Circulation. 2018;137:546-548.

6. Kario K. Global impact of 2017 American Heart Association/American College of Cardiology Hypertension Guidelines: a perspective from Japan. Circulation. 2018;137:543-545.

7. Wander GS, Ram CVS. Global impact of 2017 American Heart Association/American College of Cardiology Hypertension Guidelines: a perspective from India. Circulation. 2018;137:549-550.

8. Schifrin E. Global impact of the 2017 American College of Cardiology/ American Heart Association Hypertension Guidelines: a perspective from Canada. Circulation. 2018;137:883-885.

9. Rodríguez-Ramírez M, Simental-Mendía LE, González-Ortiz M, Martínez-Abundis E, Madero A, et al. Prevalence of prehypertension in Mexico and its association with hypomagnesemia. Am J Hypertension. 2015;28:1024-1030.

10. Jaffe MG, Young JD. The kaiser permanent Northern California story: improving hypertension control from $44 \%$ to $90 \%$ in 13 years (2000 to 2013). J Clin Hypertens. 2016;18:260-261.

11. Rosas-Peralta M, Palomo-Piñón S, Borrayo-Sánchez G, et al. Consenso de Hipertensión Arterial Sistémica en México. Rev Med Inst Mex Seguro Soc. 2016;54:6-51.

12. Borja-Aburto VH. Salud pública. México: Alfil; 2013.

13. Instituto Mexicano del Seguro Social. [Sitio web]. CHKT en línea. PREVENIMSS. Disponible en: http://www.imss.gob.mx/chkt.

14. Castañeda-Sánchez O, Ruelas-Oliveros G. Efecto de una intervención educativa en preescolares con factores de riesgo cardiovascular en Ciudad Obregón, Sonora. Aten Fam. 2015;22:77-81. 